\title{
INSYDE: a synthetic, probabilistic flood damage model based on explicit cost analysis
}

\author{
Francesco Dottori ${ }^{1, *}$, Rui Figueiredo ${ }^{2, *}$, Mario L. V. Martina ${ }^{2, *}$, Daniela Molinari ${ }^{3, *}$, and Anna Rita Scorzini ${ }^{4, *}$ \\ ${ }^{1}$ European Commission, Joint Research Centre, Ispra, Italy \\ ${ }^{2}$ Scuola Universitaria Superiore IUSS Pavia, Pavia, Italy \\ ${ }^{3}$ Dipartimento di Ingegneria Civile e Ambientale, Politecnico di Milano, Milano, Italy \\ ${ }^{4}$ Dipartimento di Ingegneria Civile, Edile-Architettura e Ambientale, Università degli Studi dell' Aquila, L'Aquila, Italy \\ *These authors contributed equally to this work.
}

Correspondence to: Rui Figueiredo (rui.figueiredo@iusspavia.it)

Received: 11 May 2016 - Published in Nat. Hazards Earth Syst. Sci. Discuss.: 17 May 2016

Revised: 3 October 2016 - Accepted: 24 October 2016 - Published: 2 December 2016

\begin{abstract}
Methodologies to estimate economic flood damages are increasingly important for flood risk assessment and management. In this work, we present a new synthetic flood damage model based on a component-by-component analysis of physical damage to buildings. The damage functions are designed using an expert-based approach with the support of existing scientific and technical literature, loss adjustment studies, and damage surveys carried out for past flood events in Italy. The model structure is designed to be transparent and flexible, and therefore it can be applied in different geographical contexts and adapted to the actual knowledge of hazard and vulnerability variables.

The model has been tested in a recent flood event in northern Italy. Validation results provided good estimates of postevent damages, with similar or superior performances when compared with other damage models available in the literature. In addition, a local sensitivity analysis was performed in order to identify the hazard variables that have more influence on damage assessment results.
\end{abstract}

\section{Introduction}

Flood damage evaluation today is a crucial component of any strategy for flood risk mitigation and management (Messner and Meyer, 2006; Messner et al., 2007; Merz et al., 2010). In particular, models and methodologies for estimating economic damages are key for evaluating and comparing flood mitigation measures and for defining flood risk management plans (Bouwer et al., 2013; Schröter et al., 2014).

Available damage models can be classified into two main classes: empirical and synthetic models (Smith, 1994; Merz et al., 2010). Empirical models use damage datasets collected from past flood events to link vulnerability and hazard variables to damage (data-driven approaches), while synthetic models adopt a more conceptual expert-based approach using hypotheses and assumptions about damage mechanisms (what-if analysis). Empirical and synthetic damage models can be employed for a variety of applications (e.g. Papathoma-Köhle et al., 2015), such as the derivation of damage functions for different types of assets, post-event damage estimation, and analysis of uncertainty sources in damage assessments.

Despite their growing importance, there are still relevant issues in the application of flood damage models (Handmer, 2003; Meyer et al., 2013). First, the relative scarcity of observed damage data is often a relevant obstacle in developing and improving existing models. Models based on data-driven approaches are especially prone to this issue because they require specific calibration to be applied in different contexts (Merz et al., 2010; Bubeck and Kreibich, 2011). Synthetic models, adopting expert-based assumptions of hazarddamage relationships, are less dependent on datasets for model derivation, though they still require additional data for calibration and validation (Smith, 1994; Merz et al., 2010).

Second, even when reliable and comprehensive datasets are available, it is generally not possible to extrapolate ade- 
quate damage functions due to the well-known complexity of damage mechanisms (Andrè et al., 2013; Cammerer et al., 2013; Scorzini and Frank, 2015). Damage computation methods based on probabilistic approaches might offer a solution to this issue (Schröter et al., 2014), yet this research topic is still relatively unanswered in literature.

Third, the evaluation of flood mitigation measures requires methodologies for estimating economic damages at both the micro-scale (e.g. building-scale strategies for vulnerability reduction) and the mesoscale (e.g. spatial planning strategies) (Schröter et al., 2014). When micro-scale strategies are considered, empirical models are less suitable because the model structure generally considers few explicative variables. For residential buildings these typically include the water depth, the building structure, and the number of floors (Messner and Meyer, 2006; Schröter et al., 2014); as a consequence, it is not possible to evaluate the effect of the full range of mitigation strategies available, such as the use of permeable materials, the moving of vulnerable components, etc. Synthetic models can overcome this limitation since their level of complexity can be designed to adapt to the required detail. Still, subjectivity in what-if analyses may result in uncertain damage estimates (Gissing and Blong, 2004). In addition, these models are often affected by a lack of transparency, which limits their applicability and transferability, as well as possible improvements (Scorzini and Frank, 2015). Indeed, in many cases the rationale behind model development (e.g. assumptions, mechanisms considered, built-in parameters) is not clearly presented and relevant variables to be used are not well explained.

Given this framework, in this paper we propose a probabilistic methodology to derive synthetic damage curves for residential buildings called INSYDE (In-depth Synthetic Model for Flood Damage Estimation). The method is based on an explicit component-by-component analysis of physical damages to buildings, which takes into account available knowledge on damage mechanisms. INSYDE is transparent and can be applied in different contexts. Implemented functions and values are clearly explained so that they can be totally or partly modified according to the physical context in which the model is applied. Conversely, the methodology allows for different levels of detail in the analysis, hence the damage model can be adapted to the actual knowledge of relevant hazard and vulnerability variables.

The damage functions composing the model have been designed using an expert-based approach with the support of existing scientific and technical literature, loss adjustment studies, and damage surveys carried out for past flood events in Italy. It is important to note that the current version presented in this paper is limited to residential building damage estimation. The general methodology, however, can be extended to other types of assets, such as commercial or industrial buildings.

Subsequently, the model was validated against loss data collected for a recent flood event in northern Italy and com- pared with the results provided by several damage models in the literature. Finally, we performed a sensitivity analysis of the model hazard parameters in order to explore in more detail the model behaviour and quantify the influence of each hazard parameter. The results and relevant findings are discussed in order to highlight strengths and weaknesses of the proposed model.

\section{Model description}

INSYDE adopts a synthetic approach consisting of the simulated, step-by-step inundation of residential buildings, and in the evaluation of the corresponding damage based on building and hazard features. Such a methodology can also be referred to as a what-if analysis.

Damages are first modelled on a component-bycomponent basis using physically based mathematical functions and are then converted into monetary terms using full replacement costs derived from reference price lists. The overall economic damage to each building $D$ is obtained by summing each of the different damage components $C_{i}$ as follows:

$D=\sum_{i=1}^{n} C_{i}=\sum_{i=1}^{n} \sum_{j=1}^{m_{i}} C_{i j}$,

where $C_{i}$ includes clean-up and removal costs, structural damage, non-structural damage, damage to finishing elements, damage to windows and doors, and damage to building systems, and $n$ is the total number of components used to define the damage. Each component $C_{i}$ is subdivided into $m_{i}$ different subcomponents $C_{i j}$, specifically referring to the reparation of the damaged elements or to their removal and replacement. The complete list of components and subcomponents is presented in Table 1.

For each subcomponent, a mathematical function describing the damage mechanism and associated cost is formulated, considering expert-based knowledge as well as available technical and scientific documentation. The general formulation can be described as follows:

$$
\begin{gathered}
C_{i j}=f(\text { event features, building characteristics, } \\
\text { unit prices }),
\end{gathered}
$$

where event features include all the physical variables describing the flood event at the building location, e.g. maximum external and internal water depth, flood duration, water quality (presence of contaminants) and sediment load. Building characteristics include all the variables that describe features and geometry of the building. Building features affect damage estimation either by modifying the functions describing damage mechanisms (e.g. system distribution, building structure) or by affecting the unit prices of the building components by a certain factor (e.g. building type, finishing 


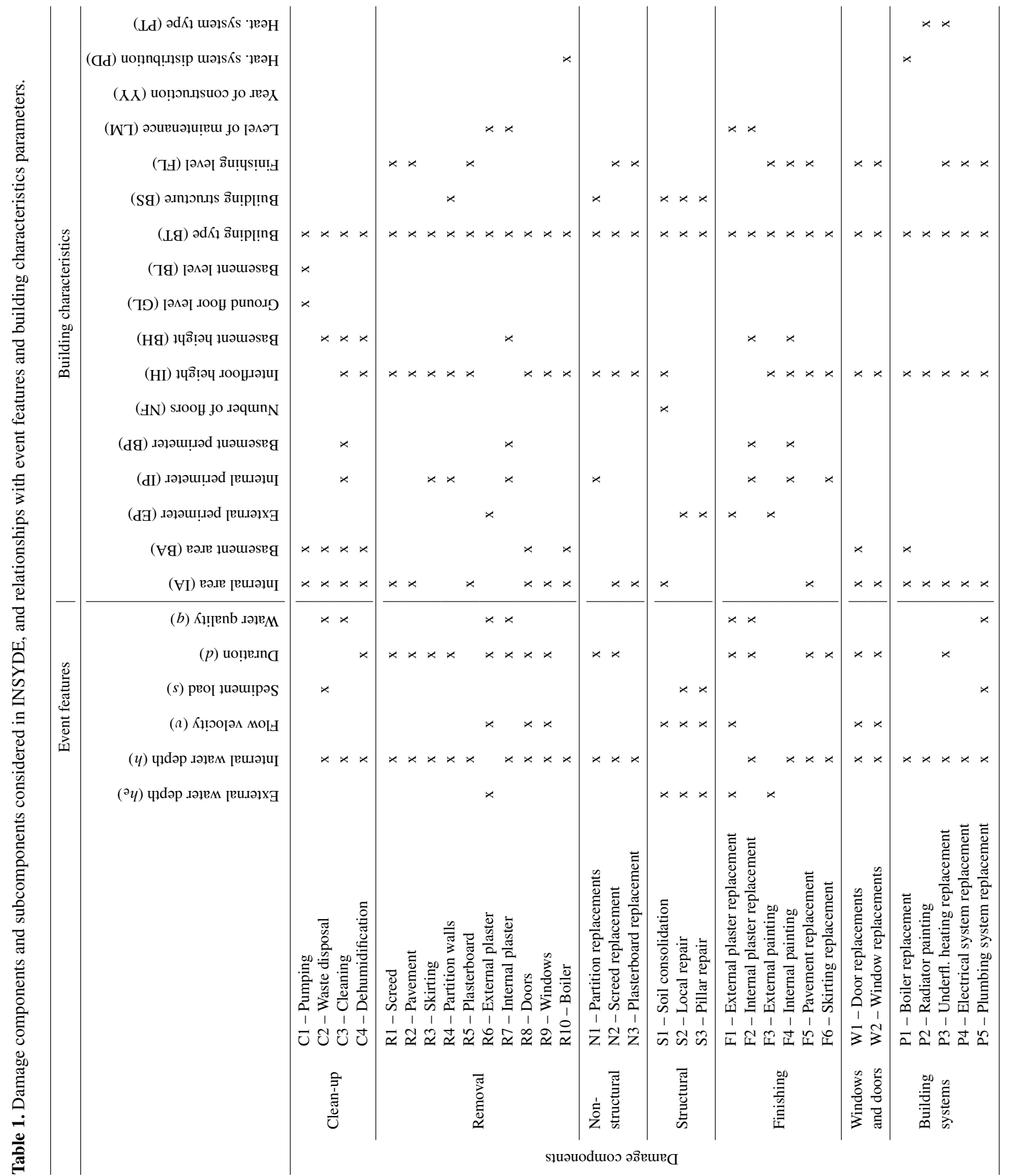


Table 2. Event features parameters considered in INSYDE.

\begin{tabular}{|c|c|c|c|c|}
\hline Variable & Description & $\begin{array}{l}\text { Unit of } \\
\text { measurement }\end{array}$ & $\begin{array}{l}\text { Range of } \\
\text { values }\end{array}$ & Default values \\
\hline$h_{\mathrm{e}}$ & Water depth outside the building & $\mathrm{m}$ & $\geq 0$ & [0; 5] Incremental step: $0.01 \mathrm{~m}$ \\
\hline$h$ & Water depth inside the building (for each floor) & $\mathrm{m}$ & {$[0 ; \mathrm{IH}]$} & $h=f\left(h_{\mathrm{e}}, \mathrm{GL}\right)$ \\
\hline$v$ & $\begin{array}{l}\text { Maximum velocity of the water } \\
\text { perpendicular to the building }\end{array}$ & $\mathrm{ms}^{-1}$ & $\geq 0$ & 0.5 \\
\hline$s$ & Sediment load & $\%$ on the water volume & {$[0 ; 1]$} & 0.05 \\
\hline$d$ & Duration of the flood event & $\mathrm{h}$ & $>0$ & 24 \\
\hline$q$ & $\begin{array}{l}\text { Water quality } \\
\text { (presence of pollutants) }\end{array}$ & - & $\begin{array}{l}0: \text { No } \\
1: \text { Yes }\end{array}$ & 1 \\
\hline
\end{tabular}

level). Conversely, the geometrical properties of the building (e.g. footprint area, number of floors) are used in the estimation of the extension of damage to each of the building components. Unit prices refer to the cost of replacement or reparation of the building components per unit of measure (e.g. door removal cost per square metre, pavement replacement cost per square metre). For the present study, unit prices are derived from Italian price lists for the year 2013 (default values are shown in Table S1 in the Supplement).

The cost for each subcomponent is determined by the unit price (up) and the extension (ext). The latter is the measure of the physical dimension of the damage (e.g. $\mathrm{m}^{2}$ of plaster damaged) and depends on the event features and building characteristics. We can therefore refer to

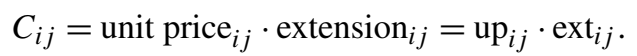

This distinction is useful for model generalization. The extension of the damage is determined only by the physical effects that the flood event causes to the building; therefore, the same approach can be applied in different countries or geographic areas, provided that the local characteristics of the buildings are accounted for. Unit prices, instead, vary from country to country or even within a country, they can also be referred to standard or default unit prices in official publications. Therefore, local price values are well identified and can be easily replaced with more suitable ones in this approach.

Tables 2 and 3 describe in detail the event features and building characteristics parameters, their unit of measurement, their range, and the default values in case no information is supplied to the model. When some of the input data are missing, another option available in the model is to sample these parameters from distributions, which also allows uncertainty analysis in input data. The damage functions and the general assumptions for all the damage subcomponents are reported in the Supplement, while Table 1 synthesizes the event features and building characteristics considered for each subcomponent function. The variables listed in Tables 2 and 3 can directly affect damage estimation in terms of ex- tension or indirectly by influencing other variables. An example of the latter case is YY (year of construction), which, as shown in Table 1, has no direct impact on the damage mechanisms of the different building subcomponents but indirectly influences the selection of other variables such as PD (heating system distribution) and PT (heating system type). Another example is NF (number of floors), which only directly affects soil consolidation despite indirectly influencing many other building components because damage on upper floors can only occur if the floors actually exist in the building. The number of flooded floors is then calculated as a function of inundation depth and interfloor height of the building (IH). Please refer to the Supplement for more details on assumptions and a description of considered damage mechanisms.

Another important aspect of the proposed approach is that several of the damage mechanisms are modelled using probabilistic functions rather than deterministic ones. The choice of the type of function is based on the authors' knowledge, consistent with the expert-based approach of INSYDE, and on the availability of information in literature. Some damage processes are well understood and, in our opinion, do not require a probabilistic treatment. For instance, we suppose that if a building is flooded then the basement will always be flooded, under the assumption that flood-proof measures to prevent this are rarely implemented. Other damage mechanisms can also be well explained, even though there is a degree of uncertainty due to building characteristics. For instance, electrical systems are considered to be damaged if some of their components are reached by flood water, but the height of these components may vary depending on the building. In this case however, we decided to overlook this uncertainty and use deterministic functions since the variability of the height of these components is usually small.

Finally, there are damage mechanisms on which the influence of hazard and building parameters cannot be determined a priori, and these mechanisms were modelled adopting a probabilistic approach. The motivation is that, even if the damage mechanism itself is known, it is impossible to de- 
Table 3. Building characteristics parameters considered in INSYDE.

\begin{tabular}{|c|c|c|c|c|}
\hline Variable & Description & Unit of measurement & Range of values & Default values \\
\hline FA & Footprint area & $\mathrm{m}^{2}$ & $>0$ & 100 \\
\hline IA & Internal area & $\mathrm{m}^{2}$ & $>0$ & $0.9 \cdot \mathrm{FA}$ \\
\hline $\mathrm{BA}$ & Basement area & $\mathrm{m}^{2}$ & $\geq 0$ & $0.5 \cdot \mathrm{FA}$ \\
\hline EP & External perimeter & $\mathrm{m}$ & $>0$ & $4 \cdot \sqrt{\mathrm{FA}}$ \\
\hline IP & Internal perimeter & $\mathrm{m}$ & $>0$ & $2.5 \cdot \mathrm{EP}$ \\
\hline $\mathrm{BP}$ & Basement perimeter & $\mathrm{m}$ & $>0$ & $4 \cdot \sqrt{\mathrm{BA}}$ \\
\hline NF & Number of floors & - & $\geq 1$ & 2 \\
\hline $\mathrm{IH}$ & Interfloor height & $\mathrm{m}$ & $>0$ & 3.5 \\
\hline $\mathrm{BH}$ & Basement height & $\mathrm{m}$ & $>0$ & 3.2 \\
\hline GL & Ground floor level & $\mathrm{m}$ & {$[-\mathrm{IH} ;>0]$} & 0.1 \\
\hline $\mathrm{BL}$ & Basement level & $\mathrm{m}$ & $<0$ & $-\mathrm{GL}-\mathrm{BH}-0.3$ \\
\hline BT & Building type & - & $\begin{array}{l}\text { 1: Detached house } \\
\text { 2: Semi-detached house } \\
\text { 3: Apartment house }\end{array}$ & 1 \\
\hline BS & Building structure & - & $\begin{array}{l}\text { 1: Reinforced concrete } \\
\text { 2: Masonry }\end{array}$ & 2 \\
\hline FL & $\begin{array}{l}\text { Finishing level } \\
\text { (i.e. building quality) }\end{array}$ & - & $\begin{array}{l}0.8: \text { low } \\
1: \text { medium } \\
1.2: \text { high }\end{array}$ & 1.2 \\
\hline LM & Level of maintenance & - & $\begin{array}{l}0.9: \text { low } \\
1: \text { medium } \\
1.1: \text { high }\end{array}$ & 1.1 \\
\hline YY & Year of construction & - & $\geq 0$ & 1994 \\
\hline PD & Heating system distribution & - & $\begin{array}{l}\text { 1: centralized } \\
\text { 2: distributed }\end{array}$ & $\begin{array}{l}1 \text { if } Y Y \leq 1990 \\
2 \text { otherwise }\end{array}$ \\
\hline PT & Heating system type & - & $\begin{array}{l}\text { 1: radiator } \\
2: \text { pavement }\end{array}$ & $\begin{array}{l}2 \text { if } Y Y>2000 \\
\text { and } F L>1 \\
1 \text { otherwise }\end{array}$ \\
\hline
\end{tabular}

terministically define, for certain hazard variables, a threshold below which no damage occurs and above which it does. For instance, it is known that plaster is usually not damaged for short duration flood events, while replacement might be necessary in case of a long duration flood (Penning-Rowsell et al., 2005). However, it is not possible to define a deterministic threshold for the variable "flood duration" because it depends on variables like the type of plaster, the season in which the flood occurs, and so on. In practice, these types of variables are usually not obtainable, or if they are, it is not possible to have a clear understanding of how they affect the damage mechanism. One could assume, for example, that the threshold value for plaster replacement is $18 \mathrm{~h}$. However, it might happen that in reality the plaster needs to be replaced even if the flood duration is less than that (e.g. 16h); conversely, it is possible that the plaster is not damaged for a flood with a longer duration $(20 \mathrm{~h}$, for example) because of the factors described above.

To account for these uncertainties, the model considers that for some of the building components, given a certain flood hazard intensity measure IM, there are two possible damage states DS, not damaged $\left(\mathrm{ds}_{0}\right)$ and damaged $\left(\mathrm{ds}_{1}\right)$, each with a probability of occurrence $p(\mathrm{~d} s)=P(\mathrm{DS}=$ $\mathrm{ds} \mid \mathrm{IM}=\mathrm{im})$. A similar approach is typically used in the field of seismic vulnerability assessment (e.g. Rossetto and Elnashai, 2003; Rota et al., 2008). Each damage state is associated with a damage ratio $R$, which represents the repair cost of the component divided by its replacement cost. In the 
case of INSYDE, for most components it is assumed that if damage occurs, full repair or replacement is necessary. Thus, when $\mathrm{DS}=\mathrm{ds}_{1}$, then $R=r_{1}=1.0$.

Within this probabilistic framework, the INSYDE model can be used to estimate building damage in two ways depending on the user's requirements. The first consists of simply calculating the expected loss of each component according to Eq. (4), using the expected damage ratio $E[R]$, which is given directly by $p\left(\mathrm{ds}_{1}\right)$ as shown in Eq. (5). This approach can be used in simpler applications where the quantification of uncertainty related to component damage states is not required.

$C_{i j}=$ unit price $_{i j} \cdot$ extension $_{i j} \cdot E[R]$

$E[R]=r_{0} p\left(\mathrm{ds}_{0}\right)+r_{1} p\left(\mathrm{ds}_{1}\right)=p\left(\mathrm{ds}_{1}\right)$

The second consists of taking into account the probabilities of occurrence of damage to the different components in order to obtain a distribution of the total building damage rather than a single value, enabling the treatment of uncertainties in the damage mechanisms considered in the model. The procedure to do this is analogous to the one presented by Porter et al. (2001). First, for each building component a number $u \sim[0,1]$ is sampled from the standard uniform distribution, and the corresponding damage state is evaluated using the inverse cumulative distribution ds $=F_{\mathrm{DS} \mid \mathrm{im}}^{-1}(u)$. The loss $C_{i j}$ is then calculated according to Eq. (6):

$C_{i j}=$ unit price $_{i j} \cdot$ extension $_{i j} \cdot r_{\mathrm{ds}}$.

The losses to each of the components are summed in order to obtain one realization of the total economic damage to the building. This process is repeated a large number of times, and a building damage distribution is computed.

It should be mentioned that the distribution of $P(\mathrm{DS}=$ $\left.\mathrm{ds}_{1} \mid \mathrm{IM}\right)$, which can be referred to as a fragility function, is not as simple to define as in the case of a simple threshold mentioned above. On the one hand, to our knowledge, no studies have been carried out on this topic in the flood damage modelling field. On the other hand, an expert-based definition of a complete fragility function is not a straightforward task. It is, however, possible to define reasonable lower and upper thresholds for IM, below which one can be reasonably sure that the probability of damage is close to 0 and above which it is approximately 1 . Following this line of thought, truncated normal distributions between those two values were adopted as fragility functions for different building components. Although this is a simplified approach, it should be viewed in light of its intended purpose, which is to integrate the probabilistic framework into INSYDE, making it more robust and realistic than a simple threshold-based model. The adopted fragility functions can easily be replaced by the user, according to each specific case and/or his/her knowledge about the behaviour of a specific building component, for example. This follows the open and transparent philosophy behind the development of the model.

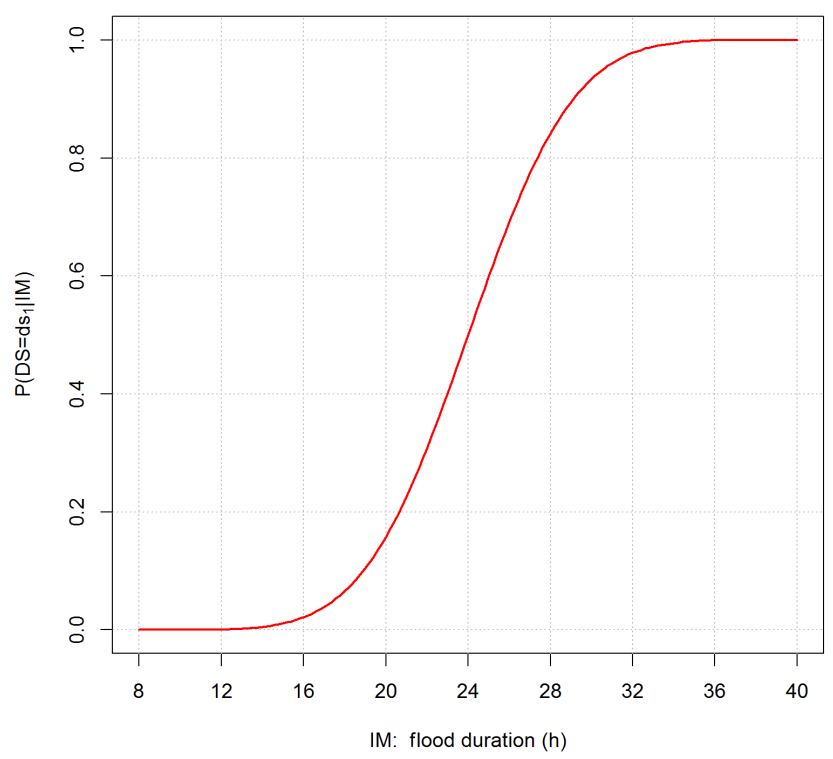

Figure 1. Fragility function for internal plaster. Here, the intensity measure of flood hazard IM is given by flood duration.

The fragility functions adopted in INSYDE can be found in the Supplement. An example is shown in Fig. 1.

In addition to expert knowledge and technical papers, the set-up of the damage functions was supported by an observational method, which helped to identify the most influential variables on damage occurrence for the different building subcomponents. In particular, an analysis has been carried out on the relation between observed damages and the damage explicative parameters (hazard and vulnerability parameters) considered by INSYDE, using highly detailed damage data for about 60 affected buildings during the November 2012 flood in the Umbria region in central Italy (Molinari et al., 2014). Chi-square hypothesis tests were performed on contingency tables based on available data, in order to analyse the possibility of any correlation between certain event and building variables and damage mechanisms on building elements. A higher correlation was found for water depth, in particular for the damage to electrical systems (significance level $\alpha=0.01$ ), windows, plumbing systems, and clean-up $(\alpha=0.05)$. Duration and water quality seemed to be less significant for damage occurrence for most of the building components, except for exterior plaster (duration, $\alpha=0.10$ and water quality, $\alpha=0.05$ ), pavement (duration, $\alpha=0.05$ ), and clean-up (water quality, $\alpha=0.10$ ). With respect to building variables, a higher correlation was found for the presence of a basement, in particular for the damage to the electrical system $(\alpha=0.01)$ and interior plaster $(\alpha=0.05)$. The outcome of this analysis was integrated with loss adjustment evaluations in recent flood events in the Emilia-Romagna region (northern Italy), and the results were used to corroborate the dependencies adopted in damage functions. 
It is important to underline that during the model design, observed damage data were essentially used to analyse the relations between hazard parameters and damage mechanisms in order to improve physical damage functions. For instance, the functions for structural damage found in literature were implemented in the model after some modifications, as they were not in line with the observed damages. Such a usage is consistent with an expert-based approach because observed data were first interpreted and then used to modify parts of the model structure rather than applied to calibrate the parameters of existing functions.

Figures 2 and 3 provide an example of damage functions developed for a default building in the case of a flood with a duration $d=24 \mathrm{~h}$, flow velocity $v=2.0 \mathrm{~m} \mathrm{~s}^{-1}$, sediment concentration $s=0.05$, and presence of pollutants $(q=1)$.

To complete the INSYDE methodology, the absolute damage figures computed can be converted into relative value by dividing them by the replacement value of the building. This value is given as a function of the building type and structure and year of construction of the building based on existing literature and official studies (Cresme-Cineas-Ania, 2014).

\section{Validation}

The model was validated using loss data of the 2010 flood collected by the municipality of Caldogno in the Veneto region in northeastern Italy. Available building loss data, related to about 300 affected buildings, were based on the "quantification of damage" forms sent out by the authorities, in the frame of the loss compensation process by the state. These data consisted of actual restoration costs, certified by original receipts and invoices. The total reported loss was estimated to be approximately EUR 7.5 million.

Aside from registered losses, the following event and building information was available (Scorzini and Frank, 2015):

- external water depth $\left(h_{\mathrm{e}}\right)$ and flow velocity $(v)$ at buildings locations, resulting from 1-D and 2-D hydraulic modelling of the flood event;

- sediment load $(s)$ : fine-grained sediment, $s=0.05$;

- floor area (FA) and number of floors (NF) of damaged buildings;

- structural type of damaged buildings (BS): almost equally distributed among reinforced concrete and masonry buildings;

- typology of damaged buildings (BT): 151 detached houses, 70 semi-detached houses, and 75 apartment buildings. A further distinction between elements with and without basements was available. In addition, a finishing level (FL) was attributed to each single building based on its quality;
- year of construction (YY) of the buildings.

The first part of the validation exercise consisted of applying INSYDE deterministically (i.e. without considering any source of uncertainty) with the previous data as input, assuming the default values in Tables 2 and 3 for missing variables. Calculated total loss was equal to EUR 7.42 million, with a relative error of $-1.7 \%$.

Figure 3, showing estimated losses against observed ones, provides a more in-depth analysis of the results. The model tended to overestimate low damages and to underestimate high ones (Fig. 3a), with a root mean square error (RMSE) equal to EUR 28 996. Nevertheless, there was a high degree of agreement between the two distributions (Fig. 3b).

The results presented above were compared with those obtained by applying other deterministic micro-scale damage functions from the literature (Scorzini and Frank, 2015). These included: Debo (1982), Dutta et al. (2003), FLEMOps (Thieken et al., 2008), and others specifically applied in damage assessment studies in Italy, i.e. Oliveri and Santoro (2000), Luino et al. (2009), and Arrighi et al. (2013).

Table 4 summarizes total loss estimates and RMSE calculated by using the selected micro-scale models and INSYDE. The output from these functions ranged from EUR 5.8 to 13 million, resulting in a maximum relative error from the reported building losses (EUR 7.5 million) of about $73.6 \%$ $(\mathrm{RMSE}=\mathrm{EUR} 34990)$, obtained with the curve of Dutta et al. (2003). The others gave similar results, with relative errors in the order of $12-23 \%$ (RMSE $\approx$ EUR 28000 29600), excluding the function of Luino et al. (2009), which overestimated the total loss by more than $45 \%$ $(\mathrm{RMSE}=\mathrm{EUR} 30230)$. The relatively high value of the RMSE obtained from the application of the different models was mainly due to the intrinsic natural spread of damage data (Smith, 1994), which makes a perfect fit of a damage model practically impossible. From this perspective, INSYDE, supported by a physically based methodology, provided encouraging results, with a relatively small observed RMSE and minimum relative error $(-1.7 \%)$ on the total damage figure. It should be noted that the latter result is arguably the most important measure since at spatial scales such as the one in this case study, it is usually more relevant to capture the overall damage distribution and total value than the individual, building-by-building damage.

Notwithstanding, the second part of the validation exercise consisted of performing a building-by-building comparison of observed and modelled losses, with the objective of determining the degree of agreement between them after considering in a simplified manner some of the potential sources of uncertainty. This was done by estimating loss ranges - both observed and modelled - for each building, and then computing the hit rate (HR) as the fraction between the number of cases in which there was an overlap between them and the total number of buildings. 

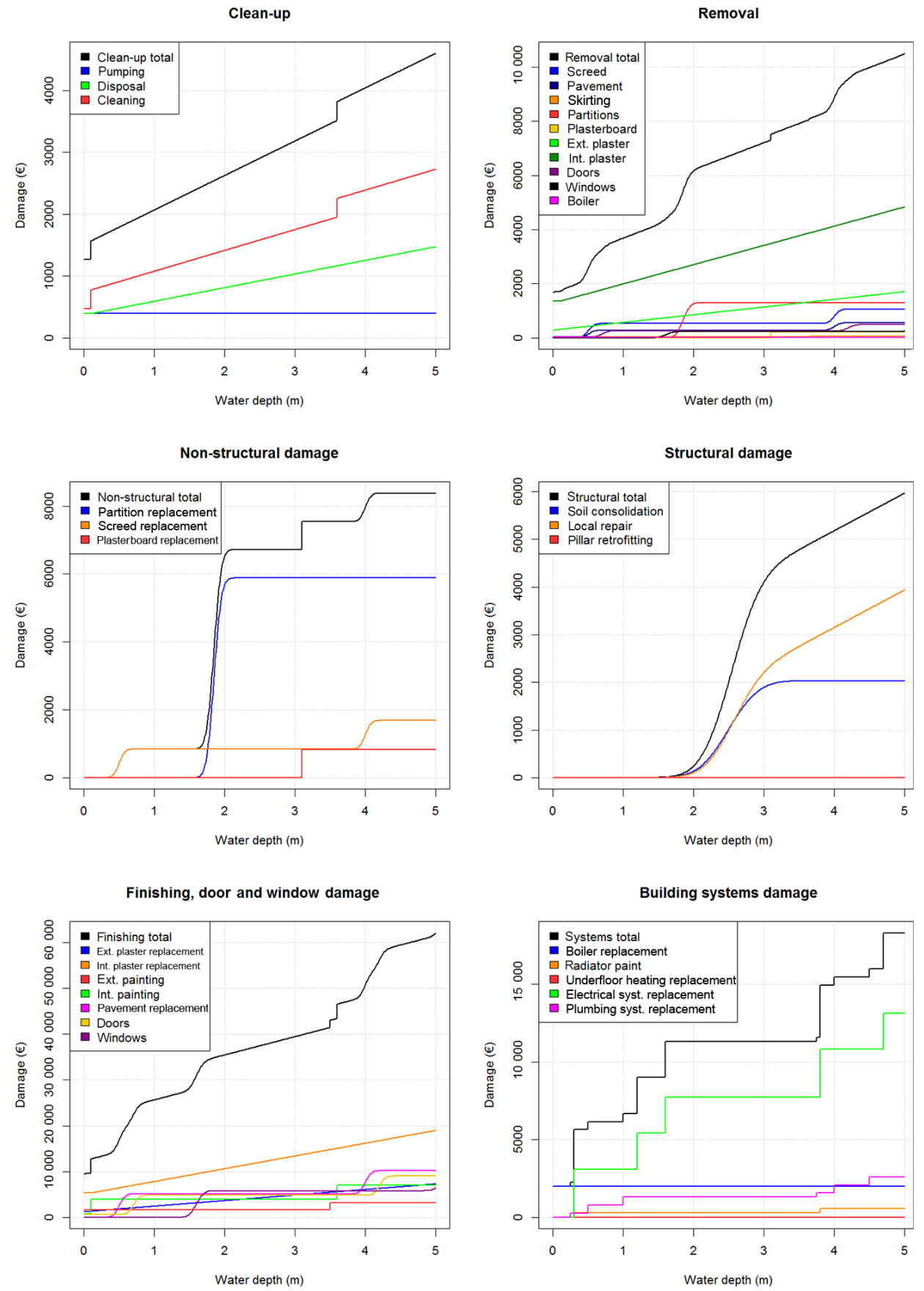

Figure 2. Example of INSYDE damage functions for all building subcomponents, considering the following event variables: flow velocity $=2.0 \mathrm{~m} \mathrm{~s}^{-1}$, flood duration $=24 \mathrm{~h}$, sediment concentration $=0.05$, and water quality $=$ presence of pollutants.

Table 4. Comparison of loss estimates produced by INSYDE and other models in literature.

\begin{tabular}{lrrrrrrr}
\hline & $\begin{array}{r}\text { Debo } \\
(1982)\end{array}$ & $\begin{array}{r}\text { Dutta et al. } \\
(2003)\end{array}$ & FLEMOps & $\begin{array}{r}\text { Oliveri and Santoro } \\
(2000)\end{array}$ & $\begin{array}{r}\text { Luino et al. } \\
(2009)\end{array}$ & $\begin{array}{r}\text { Arrighi et al. } \\
(2013)\end{array}$ & $\begin{array}{r}\text { INSYDE } \\
\end{array}$ \\
\hline Calculated loss [EUR million] & 5.79 & 13.10 & 6.58 & 5.93 & 10.95 & 6.34 \\
Relative error [\%] & -23.3 & +73.6 & -12.8 & -21.4 & +45.2 & -16.0 \\
RMSE [EUR] & 28302 & 34990 & 28116 & 27972 & 30230 & 29622 & 28996 \\
\hline
\end{tabular}



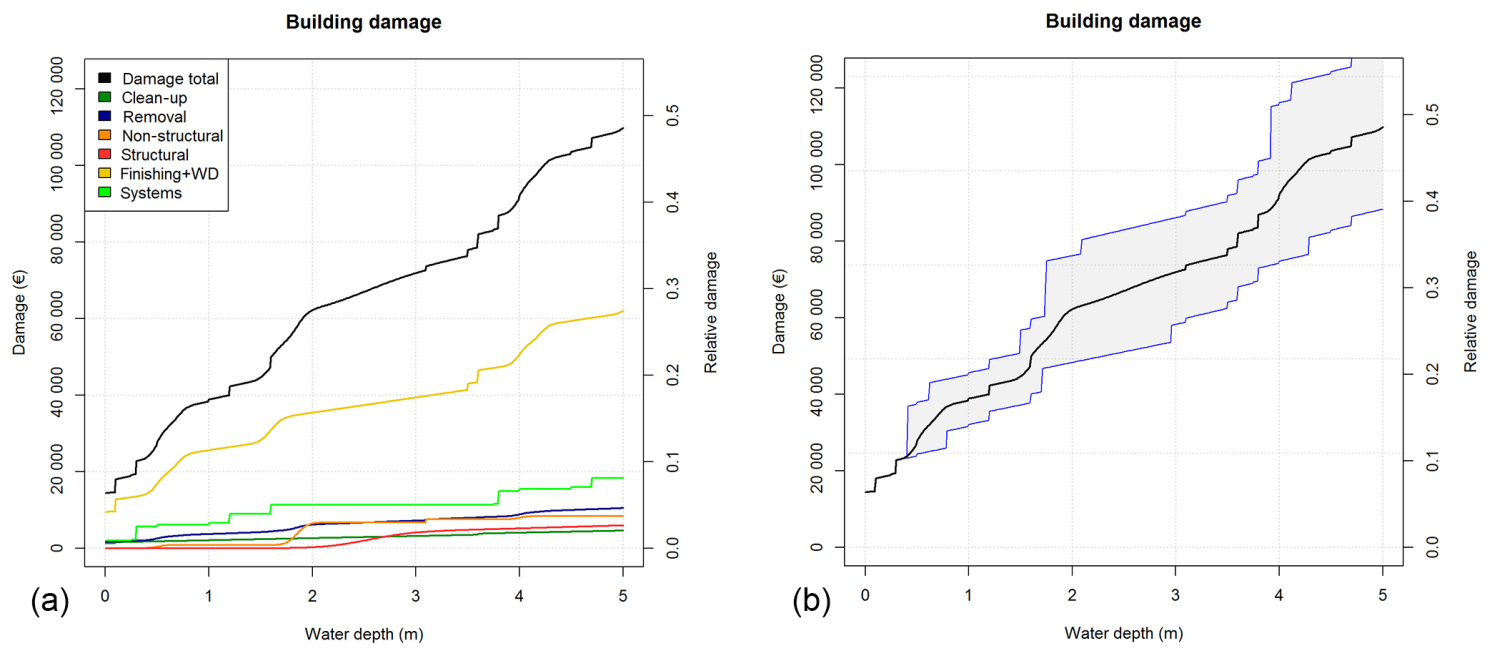

Figure 3. Example of INSYDE damage functions considering the following event variables: flow velocity $=2.0 \mathrm{~ms}^{-1}$, flood duration $=$ $24 \mathrm{~h}$, sediment concentration $=0.05$, and water quality $=$ presence of pollutants. (a) Damage functions for entire building and different building components. (b) Total building damage function with 5th and 95th percentiles of modelled damages representing uncertainty due to damage mechanisms.

In order to reflect the uncertainty in damage data, the observed loss range for each building was assumed to be $\pm 25 \%$ of the reported value. This assumption was related to the large degree of subjectivity and heterogeneous criteria of assessment that usually characterize loss estimations based on the restoration costs, even if certified by receipts and invoices. In fact, in each building, the judgment on the opportunity and the economic convenience of an intervention is often performed by a different construction company. Regarding modelled loss, the 5-95th percentile interval of loss distributions were considered. The distributions were computed using a Monte Carlo approach, accounting for uncertainties not only in the damage mechanisms (as described in Sect. 2) but also in input data (Table 5).

Given these assumptions, the hit rate for the 2010 flood event was $56 \%$. This is a reasonably good result, considering that only a limited number of sources of uncertainty were considered and that their quantification was done in a simplified and rather conservative manner. In addition, it should be mentioned that this part of the validation exercise is extremely demanding in the sense that a simplified model of reality is used to estimate losses on a building-by-building basis. Even with its detailed, probabilistic structure, INSYDE simply cannot account for some of the building-to-building variability. There is a level of detail past which uncertainties become aleatory, meaning it is not reasonably possible to reduce them using damage models such as this (Der Kiureghian and Ditlevsen, 2009), and those uncertainties are not accounted for.

To conclude, the obtained validation results unequivocally show that INSYDE is able to produce accurate damage estimations and explain reasonably well a part of the uncertainty that inherently exists in flood damage estimations.
Table 5. Distributions adopted for the input variables in the validation exercise.

\begin{tabular}{lr}
\hline Input variable & Distribution \\
\hline & Event features \\
\hline Water depth $\left(h_{\mathrm{e}}\right)$ & $U\left(h_{\mathrm{e}}-0.3, h_{\mathrm{e}}+0.3\right)$ \\
Velocity $(v)$ & $U(0.7 v, 1.3 v)$ \\
Sediment load $(s)$ & $U(0,0.10)$ \\
\hline \multicolumn{2}{c}{ Building characteristics } \\
\hline Ground level (GL) & $U\{0,0.10, \ldots, 0.40,0.50\}$ \\
Level of maintenance (LM) & $U\{1,1.10\}$ \\
\hline
\end{tabular}

\section{Sensitivity analysis}

The damage dataset used to validate the model in Sect. 3 did not allow full investigation of the model behaviour. The limited total flood extent and the slow flow processes that occurred in the study area resulted in low values of hazard variables like water depth, flow velocity, and sediment load. Therefore, the test did not allow assessment of the influence of these parameters in determining the damage, that is the sensitivity of the model structure to high values of the hazard variables. To further explore the importance of each of these parameters, we performed a local sensitivity analysis. In this application, the damage was computed by varying alternately each hazard parameter while the others were kept constant. The building characteristics variables have not been analysed at this stage, nor has the uncertainty related with the probabilistic modelling of some of the damage mechanisms (see Sect. 5 for a more detailed discussion). 

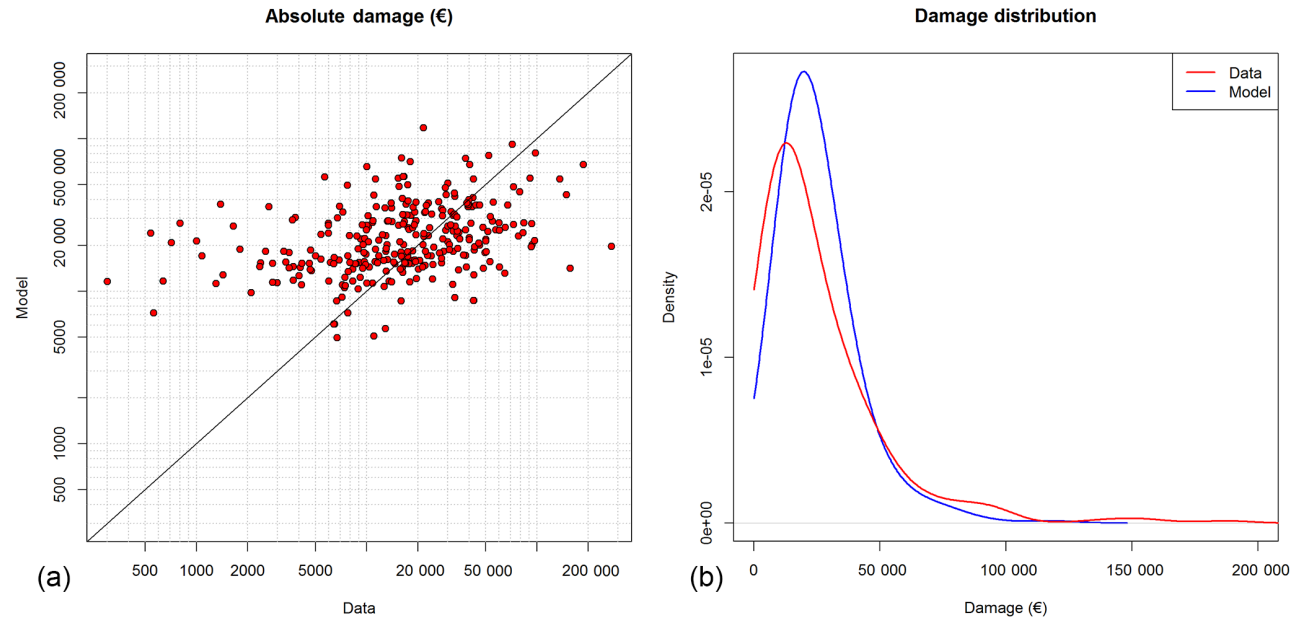

Figure 4. Comparison of observed against modelled loss for the buildings affected by the 2010 flood in Caldogno. (a) Scatter plot. (b) Kernel density plots.

Local sensitivity analysis: spider plot

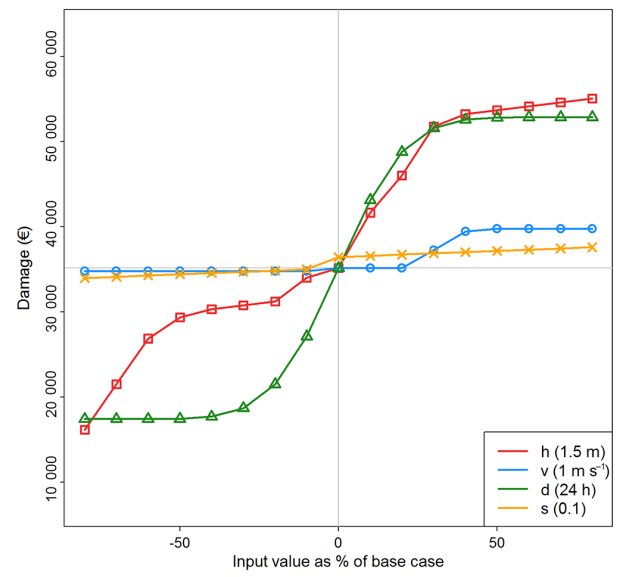

Local sensitivity analysis: tornado plot

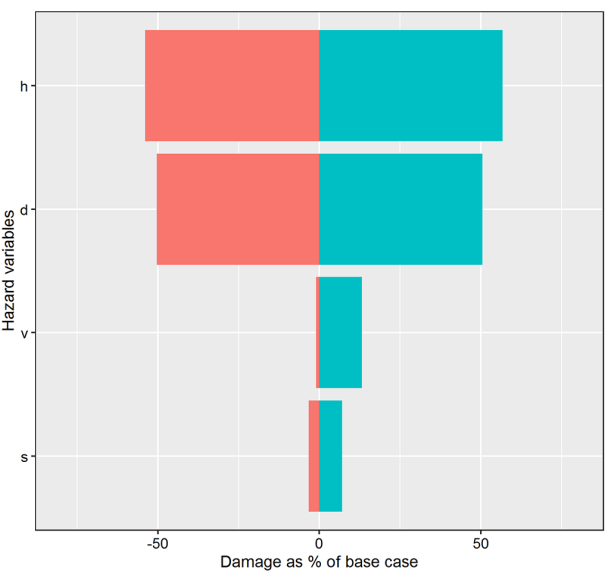

Figure 5. Results of the local sensitivity analysis in case of low velocity, long duration flood.

Two different flood conditions have been considered to explore the model behaviour in different conditions: a low velocity, long duration flood and, conversely, a high velocity, short duration flood event. For the first case, the fixed values of depth, velocity, duration, and sediment load were respectively $h=1.5 \mathrm{~m}, v=1.0 \mathrm{~m} \mathrm{~s}^{-1}, d=24 \mathrm{~h}$ and $s=0.10$. For the second case, the values were $h=2.0 \mathrm{~m}, v=2.0 \mathrm{~m} \mathrm{~s}^{-1}$, $d=10 \mathrm{~h}$ and $s=0.10$.

Computations were performed considering a standard reinforced concrete building with two floors and a basement, $100 \mathrm{~m}^{2}$ of floor area, and a high finishing level. The other building characteristics were set using the previously mentioned default values.

Figures 5 and 6 summarize the results of the local sensitivity analysis in the two chosen flood conditions, showing the relative influence of each hazard variable in determining the total economic damage. As expected, water depth is the most influential parameter since all the damage functions directly depend on it. Relative changes in flood duration have much more impact in low velocity, long duration events, while the relevance of velocity is more evident at higher values, when structural damages can become important. In both scenarios sediment load has a relatively marginal importance. The influence of water quality $q$ is not included in Figs. 4 and 5 because it is a binary variable and, therefore, cannot be increased or decreased incrementally and directly compared with the other variables. Both base cases were thus computed considering the absence of pollutants $(q=0)$. To illustrate the influence of this hazard variable on model results, we computed the same two base cases separately considering the presence of pollutants $(q=1)$. The resulting relative increase in damage for the presence of pollutants ranges from around 30 to $45 \%$. 


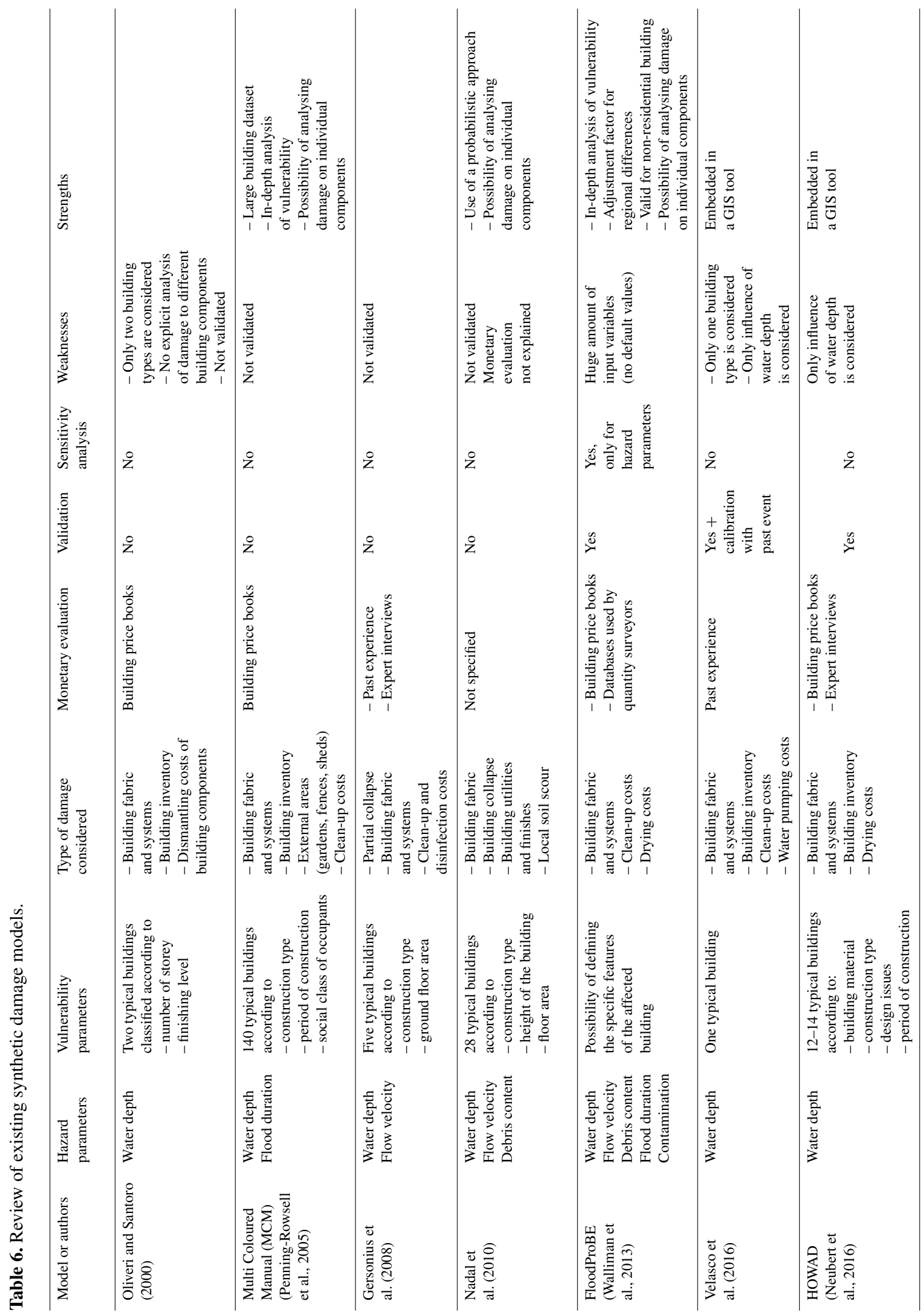



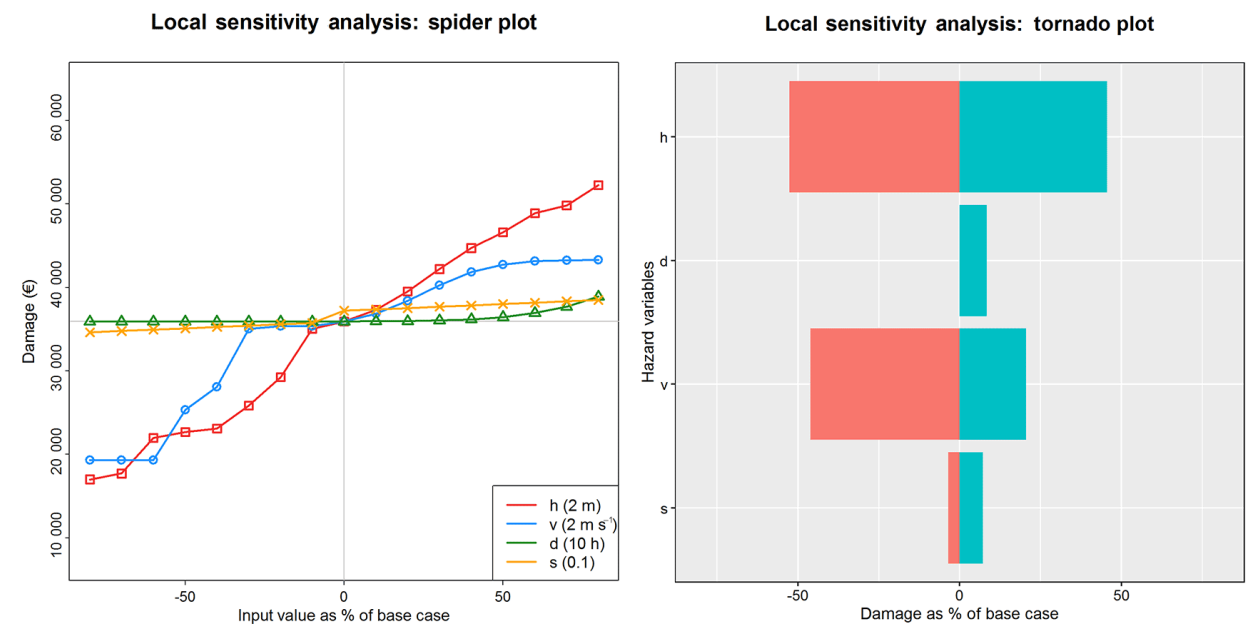

Figure 6. Results of the local sensitivity analysis in the case of high velocity, short duration flood.

\section{Critical analysis}

As introduced in Sect. 2, the approach followed in INSYDE was derived from a detailed analysis of present state-of-theart synthetic flood damage modelling for the residential sector, as depicted in Table 6. The table reports, for the main models found in the literature: considered hazard and vulnerability parameters, the estimated types of damage, the approach for the monetary evaluation of damage, whether or not models have been validated, and whether or not a sensitivity analysis has been performed. Starting from this analysis, the main strengths of existing models were identified and incorporated in INSYDE. Likewise, INSYDE tries to overcome the limitations of available approaches.

As far as hazard and vulnerability are concerned, similar to the model developed within the FloodProBE project (Walliman et al., 2013), INSYDE allows consideration of all the hazard parameters that were found to be significant in the literature, namely water depth, velocity, sediment and contaminant loads, and flood duration (Kelman and Spence, 2004; Thieken et al., 2005; Kreibich et al., 2009; Merz et al., 2010). Moreover, the vulnerability features of any specific building can be defined by means of a set of parameters (such as building size, type, structure, finishing level, maintenance level, etc.), allowing for an in-depth analysis of vulnerability (see the FloodProBE and the MCM models). This helps overcome the problem of representing the entire building stock by means of a set of predefined building types presently characterizing the majority of models. Conversely, in practical flood damage assessments, collecting all the required information on event and building features necessary for defining the input parameters used in INSYDE (Tables 2, 3) may not always be straightforward. Nevertheless, when some of these data are missing, the flexibility of the model allows the user to choose between two different options. The first, which can be suitable for rapid flood damage estimations, consists of applying the default values for the different parameters listed in Tables 2 and 3. This approach, however, may result in estimation errors and does not allow the treatment of uncertainties related to input data. These problems can be overcome by using the more detailed option of sampling these parameters from distributions instead (defined beforehand on a caseby-case basis), taking advantage of the probabilistic structure implemented in the model.

In regard to estimated damages, INSYDE presents two main strengths. First, like the FloodProBE and MCM (Penning-Rowsell et al., 2005) models, damage functions are derived component by component, which allows an in-depth analysis and description of damage mechanisms (Sect. 2 and Supplement). Second, not only losses to the building fabric and functions (e.g. systems) are modelled, but also costs related to cleaning the building, removing water and waste, and drying, which can represent an important share of the total economic damage in some cases. Damage to inventories is not considered at the moment because inventories present a higher variability than the building fabric, requiring a mixed empirical-synthetic approach. It is also important to note that in the current version the model considers only the potential damage, while factors that can affect damage, such as flood warning, preparedness, and precautionary measures, are not incorporated. Additional corrective coefficients should be used in order to adjust potential for actual losses (Smith, 1994; Thieken et al., 2005; Messner and Meyer, 2006; Poussin et al., 2015).

Regarding the monetary estimation of damage, INSYDE first estimates damages in physical terms. This is an important feature because physical measures are undisputable, while associated monetary values depend on the estimation method, underlying assumptions, stakeholders, etc. The analysis of damage in physical units supplies unambiguous estimates that can be used as the base for different economic evaluations. In INSYDE, the monetary translation is carried 
out by using building price books that can be updated and adapted to the region of implementation of the model. This way, the model can be easily applied to different geographical regions.

Another important feature of INSYDE regards the possible treatment of uncertainty embodied in the model structure. While the contribution of hazard components of risk to total damage uncertainty has been highlighted in several research works (Merz and Thieken, 2009; Merz et al., 2010; de Moel and Aerts, 2011; Thieken et al., 2014), relatively few studies present methods to explicitly account for uncertainty in damage estimations. Egorova et al. (2008) assessed uncertainties in the value of elements at risk and developed a methodology for incorporating uncertainties in depth-damage curves. Schröter et al. (2014) applied eight flood damage models with different levels of complexity to predict relative building damage in residential sectors for five historic flood events in Germany. The authors observed that the use of additional explanatory variables aside from the water depth improved the predictive capability of models, especially in applications to different regions and different flood events. In addition, models based on probabilistic structure (e.g. Bayesian networks) were more reliable than deterministic models.

In such a context, the main findings from the literature were taken into account in the development of the INSYDE model structure and respective $\mathrm{R}$ program, which enables the explicit analysis of input data and damage mechanism uncertainties, as previously described. It should be noted that it is the first time that uncertainty in damage mechanisms is included in a synthetic damage model. From this point of view, the probabilistic approach adopted in the model is an innovation in these types of models.

In this article, we have included a local sensitivity analysis of individual hazard parameters with the aim of illustrating the behaviour of the model and performing a "sanity check" on model results. An in-depth analysis of model uncertainty was not performed since we felt it would be unpractical and beyond the scope of this paper, which is focused on model structure. Indeed, for a comprehensive analysis of all possible sources of uncertainty we should take into account physical damage mechanisms together with the other model components such as economic damage functions, influence of hazard and vulnerability parameters, and probabilistic functions. Therefore, an in-depth analysis of model sensitivity and uncertainty is planned as a follow-up to the present research work.

\section{Conclusions}

In this paper, we present a new synthetic damage model called INSYDE. The model incorporates the latest developments in flood damage modelling and has been designed to be a flexible and transparent methodology, suitable for a variety of applications regarding damage assessment, vulnerabil- ity analysis of buildings, and analysis of uncertainty sources. In particular, the adopted probabilistic approach represents a first attempt to address the uncertainty issues regarding model damage mechanisms and parameters.

Model validation in a test case in Italy showed that INSYDE can provide good estimates of post-event flood losses, with similar or superior performances when compared with other damage models available in the literature. The validation exercise also showed that the model is able to explain a part of the uncertainty that inherently exists in flood loss estimations reasonably well.

Despite having been developed and tested with Italian case studies, the flexibility of the model structures allows for easy modification of both the model structure (i.e. damage functions) and the model parameters (such as building characteristics and unitary prices) for application in other countries. For the same reason, the structure of INSYDE makes it adaptable, with appropriate modifications, for flood damage assessment of other types of assets, such as building contents or commercial and industrial buildings.

\section{Data availability}

In order to increase the transparency and reproducibility of the methodology, the model functions are available for download as R open source code, currently hosted on GitHub (https://github.com/ruipcfig/insyde/). Thus, users have the possibility of applying INSYDE to compute flood damage for the different building types of interest and for any reference flood scenario. Furthermore, the model can be fully customized as users can change the value of model parameters and reference prices for the monetary evaluation of damage, as well as the different damage functions themselves. We believe that the use of open-access, transparent damage models can greatly improve the existing vulnerability models and help vulnerability assessment studies in areas where few damage datasets and models are available.

\section{The Supplement related to this article is available online at doi:10.5194/nhess-16-2577-2016-supplement.}

Acknowledgements. The authors gratefully acknowledge the region of Umbria for providing damage data for the 2012 flood.

Edited by: B. Merz

Reviewed by: S. Fuchs and one anonymous referee

\section{References}

André, C., Monfort, D., Bouzit, M., and Vinchon, C.: Contribution of insurance data to cost assessment of coastal flood damage to residential buildings: insights gained from Johanna (2008) and 
Xynthia (2010) storm events, Nat. Hazards Earth Syst. Sci., 13, 2003-2012, doi:10.5194/nhess-13-2003-2013, 2013.

Arrighi, C., Brugioni, M., Castelli, F., Franceschini, S., and Mazzanti, B.: Urban micro-scale flood risk estimation with parsimonious hydraulic modelling and census data, Nat. Hazards Earth Syst. Sci., 13, 1375-1391, doi:10.5194/nhess-13-13752013, 2013.

Bouwer, L. M., Papyrakis, E., Poussin, J., Pfurtscheller, C., and Thieken, A. H.: The Costing of Measures for Natural Hazard Mitigation in Europe, Natural Hazards Review, 15, 04014010, doi:10.1061/(ASCE)NH.1527-6996.0000133, 2013.

Bubeck, P. and Kreibich, H.: Natural Hazards: direct costs and losses due to the disruption of production processes, CONHAZ, Report WP1, D1.2, 2011.

Cammerer, H., Thieken, A. H., and Lammel, J.: Adaptability and transferability of flood loss functions in residential areas, Nat. Hazards Earth Syst. Sci., 13, 3063-3081, doi:10.5194/nhess-133063-2013, 2013.

Cresme-Cineas-Ania: Definizione dei costi di (ri)costruzione nell'edilizia, Cineas (Ed.), 1, 1-247, 2014.

Debo, T. N.: Urban flood damage estimation curves, J. Hydr. Eng. Div.-ASCE, 108, 1059-1069, 1982.

de Moel, H. and Aerts, J. C. J. H.: Effect of uncertainty in land use, damage models and inundation depth on flood damage estimates, Nat. Hazards, 58, 407-425, doi:10.1007/s11069-0109675-6, 2011.

Der Kiureghian, A. and Ditlevsen, O.: Aleatory or epistemic? Does it matter?, Struct. Saf., 31, 105-112, doi:10.1016/j.strusafe.2008.06.020, 2009.

Dutta, D., Herath, S., and Musiake, K.: A mathematical model for flood loss estimation, J. Hydrol., 277, 24-49, doi:10.1016/S0022-1694(03)00084-2, 2003.

Egorova, R., Van Noortwuk, J. M., and Holterman, S. R.: Uncertainty in flood damage estimation, International Journal of River Basin Management, 6, 139-148, doi:10.1080/15715124.2008.9635343, 2008.

Gersonius, B., Zevenbergen, C., Puyan, N., and Billah, M. M. M.: Efficiency of private flood proofing of new buildings-adapted redevelopment of a floodplain in the Netherlands, WIT Trans. Ecol. Envir., 118, 247-259, doi:10.2495/FRIAR080241, 2008.

Gissing, A. and Blong, R.: Accounting for variability in commercial flood damage estimation, Aust. Geogr., 35, 209-222, 2004.

Handmer, J.: The chimera of precision: Inherent uncertainties in disaster loss assessment, Australian Journal of Emergency Management, 18, 88-97, 2003.

Kelman, I. and Spence, R.: An overview of flood actions on buildings, Eng. Geol., 73, 297-309, doi:10.1016/j.enggeo.2004.01.010, 2004.

Kreibich, H., Piroth, K., Seifert, I., Maiwald, H., Kunert, U., Schwarz, J., Merz, B., and Thieken, A. H.: Is flow velocity a significant parameter in flood damage modelling?, Nat. Hazards Earth Syst. Sci., 9, 1679-1692, doi:10.5194/nhess-9-1679-2009, 2009

Luino, F., Bidoccu, M., Cirio, C. G., Agangi, A., Giulietto, W., Godone, F., and Nigrelli, G.: Application of a model to the evaluation of flood damage, Geoinformatica, 13, 339-353, doi:10.1007/s10707-008-0070-3, 2009.
Merz, B. and Thieken, A. H.: Flood risk curves and uncertainty bounds, Nat. Hazards, 51, 437-458, doi:10.1007/s11069-0099452-6, 2009.

Merz, B., Kreibich, H., Schwarze, R., and Thieken, A.: Review article "Assessment of economic flood damage", Nat. Hazards Earth Syst. Sci., 10, 1697-1724, doi:10.5194/nhess-10-16972010, 2010.

Messner, F. and Meyer, V.: Flood damage, vulnerability and risk perception: challenges for flood damage research, in: Flood Risk Management: Hazards, Vulnerability and Mitigation Measures, edited by: Schanze, J., Zeman, E., and Marsalek, J., Springer Netherlands, 149-167, doi:10.1007/978-1-4020-45981_13, 2006.

Messner, F., Penning-Rowsell, E., Green, C., Meyer, V., Tunstall, S., and van der Veen, A.: Evaluating Flood damages: guidance and recommendations on principles and methods, FLOODsite, Report Number T09-06-01, 178 pp., 2007.

Meyer, V., Becker, N., Markantonis, V., Schwarze, R., van den Bergh, J. C. J. M., Bouwer, L. M., Bubeck, P., Ciavola, P., Genovese, E., Green, C., Hallegatte, S., Kreibich, H., Lequeux, Q., Logar, I., Papyrakis, E., Pfurtscheller, C., Poussin, J., Przyluski, V., Thieken, A. H., and Viavattene, C.: Review article: Assessing the costs of natural hazards - state of the art and knowledge gaps, Nat. Hazards Earth Syst. Sci., 13, 1351-1373, doi:10.5194/nhess-13-1351-2013, 2013.

Molinari, D., Menoni, S., Aronica, G. T., Ballio, F., Berni, N., Pandolfo, C., Stelluti, M., and Minucci, G.: Ex post damage assessment: an Italian experience, Nat. Hazards Earth Syst. Sci., 14, 901-916, doi:10.5194/nhess-14-901-2014, 2014.

Nadal, N. C., Zapata, R. E., Pagàn, I., Lopez, R., and Agudelo, J.: Building damage due to riverine and coastal floods, J. Water Res. Pl.-ASCE, 136, 327-336, doi:10.1061/(ASCE)WR.19435452.0000036, 2010.

Neubert, M., Naumann, T., Hennersdorf, J., and Nikolowski, J.: The Geographic Information System-based flood damagesimulation model HOWAD, Journal of Flood Risk Management, 9, 36-49, doi:10.1111/jfr3.12109, 2016.

Oliveri, E. and Santoro, M.: Estimation of urban structural flood damages: the case study of Palermo, Urban Water, 2, 223-234, doi:10.1016/S1462-0758(00)00062-5, 2000.

Papathoma-Köhle, M., Zischg, A., Fuchs, S., Glade, T., and Keiler, M.: Loss estimation for landslides in mountain areas - An integrated toolbox for vulnerability assessment and damage documentation, Environ. Modell. Softw., 63, 156-169, doi:10.1016/j.envsoft.2014.10.003, 2015.

Penning-Rowsell, E., Johnson, C., Tunstall, S., Tapsell, S., Morris, J., Chatterton, J., and Green, C.: The benefits of flood and coastal risk management: a handbook of assessment techniques, Middlesex University Press, UK, 2005.

Porter, K. A., Kiremidjian, A. S., and LeGrue, J. S.: Assemblybased vulnerability of buildings and its use in performance evaluation, Earthq. Spectra, 17, 291-312, doi:10.1193/1.1586176, 2001.

Poussin, J. K., Botzen, W. W., and Aerts, J. C.: Effectiveness of flood damage mitigation measures: Empirical evidence from French flood disasters, Global Environ. Chang., 31, 74-84, doi:10.1016/j.gloenvcha.2014.12.007, 2015.

Rossetto, T. and Elnashai, A.: Derivation of vulnerability functions for European-type RC structures based on observa- 
tional data, Eng. Struct., 25, 1241-1263, doi:10.1016/S01410296(03)00060-9, 2003

Rota, M., Penna, A., and Strobbia, C. L.: Processing Italian damage data to derive typological fragility curves, Soil Dyn. Earthq. Eng., 28, 933-947, doi:10.1016/j.soildyn.2007.10.010, 2008.

Schröter, K., Kreibich, H., Vogel, K., Riggelsen, C., Scherbaum, F., and Merz, B.: How useful are complex flood damage models?, Water Resour. Res., 50, 3378-3395, doi:10.1002/2013WR014396, 2014

Scorzini, A. R. and Frank, E.: Flood damage curves: new insights from the 2010 flood in Veneto, Italy, Journal of Flood Risk Management, doi:10.1111/jfr3.12163, online first, 2015.

Smith, D. I.: Flood damage estimation - A review of urban stagedamage curves and loss functions, Water SA, 20, 231-238, 1994.

Thieken, A. H., Müller, M., Kreibich, H., and Merz, B.: Flood damage and influencing factors: New insights from the August 2002 flood in Germany, Water Resour. Res., 41, W12430, doi:10.1029/2005WR004177, 2005
Thieken, A. H., Olschewski, A., Kreibich, H., Kobsch, S., and Merz, B.: Development and evaluation of FLEMOps - a new flood loss estimation MOdel for the private sector, in: Flood recovery, innovation and response, edited by: Proverbs, D., Brebbia, C. A., and Penning-Rowsell, E., WIT Press, Southampton, UK, 315-324, 2008.

Thieken, A. H., Apel, H., and Merz, B.: Assessing the probability of large-scale flood loss events: a case study for the river Rhine, Germany, Journal of Flood Risk Management, 8, 247262, doi:10.1111/jfr3.12091, 2014.

Velasco, M., Cabello, A., and Russo, B.: Flood damage assessment in urban areas. Application to the Raval district of Barcelona using synthetic depth damage curves, Urban Water J., 13, 426-440, doi:10.1080/1573062X.2014.994005, 2016.

Walliman, N., Baiche, B., Odgen, R., Tagg, A., and Escarameia, M.: Estimation of repair costs of individual non-domestic buildings damaged by floods, International Journal of Safety and Security Engineering, 3, 289-305, doi:10.2495/SAFE-V0-N0-1-16, 2013. 